\title{
In the Wake of Terrorist Attack, Hatred May Mask Fear
}

Jennifer J. Freyd*

University of Oregon

Reactions of anger, rage, and hatred in the wake of September 11 terrorist attack are considered in light of the psychology of emotion and stress. Acknowledging underlying grief and fear through self-reflection, writing, and social communication is likely to reduce unchecked anger, rage, and hatred. Hate crimes may also have some psychological bases in responses to stress called "flight-or-fight." When flight is not an option, identifying and hating an enemy may have had evolutionary value for survival. This response creates harm in the current situation. An alternative cooperative response to stress, called "tend-and-befriend" by researchers, will be more helpful.

In Wyoming an angry group of shoppers chased a woman and her children from a Wal-Mart, apparently because the woman and children were Muslim. In New York a young Manhattan couple yelled insults at a Lebanese American who was searching for survivors from the arts center he had run at the World Trade Center. A mosque in Denton, Texas, was fire-bombed.

Why have these and other similar expressions of hostility toward people of Middle Eastern heritage already occurred across the United States following the September 11 terrorist attack (cnn.com, 2001; Thomson, 2001)? Surely we know that all Arabs or all Muslims are no more responsible for the horrific tragedy than are all Irish or all Christians responsible for terrorism in northern Ireland. Surely we do not want to repeat acts reminiscent of our own history of severely mistreating innocent Japanese Americans during World War II. Surely we don't want to engage in the same sort of racism and hatred of innocent people that we find so

\footnotetext{
*Correspondence concerning this article should be addressed to Jennifer J. Freyd, Psychology Department, 1227 University of Oregon, Eugene, OR 97403-1227 [e-mail: jif@ dynamic.uoregon.edu]. A version of this commentary was published in the Eugene Oregon city newspaper the Register-Guard on September 24, 2001.
} 
abhorrent in other lands. If we know all this, why are we displaying hostility toward innocent people?

As a research psychologist I struggle to understand these reactions. Part of the answer may reside in the way we cope with strong emotions. In the wake of the September 11 tragedy, emotions of fear, sadness, and anger are to be expected. However, it is important to know that anger, for many, is an "easier" emotional state than is grief or fear. Although there is much to be angry about, there is also much to grieve and much understandable fear. One way we often cope with sadness or fear is by focusing our attention on our anger. Particularly when the fear is high, rage may be a way to feel safer and in control (Shay, 1994). In other words, anger and rage can be used to mask emotions of sadness and fear.

Although anger can be an appropriate response to threat or injustice, hiding behind anger for a prolonged period can be harmful—both to the person hiding behind the anger and to those around that person (Shay, 1994). Underlying feelings of grief and fear may fester. And anger may turn into rage and hatred. Strong emotion that is not addressed can harm the body and mind in all sorts of ways. In contrast, much research shows that acknowledging grief and fear through selfreflection, writing, and social communication is healthy for the individual doing the acknowledging (Pennebaker, 1997).

Equally important, hiding behind anger can cause us to harm others. We may seize on convenient targets to vent the anger. We may feel hatred and we may behave with prejudice. Even if we don't act out our anger, we may be unavailable emotionally to other people if we are denying our own fear and grief.

Research in psychology provides some insight into the relationship between fear, anger, and hatred. Most animals naturally respond to threat with either flight or fight. When flight is not an option we are likely, at a very basic psychological and physiological level, to feel the need to fight (Maier, Watkins, \& Fleshner, 1994). Anger, rage, and hatred of the enemy is one way our minds might try to help our bodies prepare for a frightening survival situation. The problem is that this basic psychological response evolved for one-on-one threat situations, but the response is often poorly suited to our complex modern world. Anger in this context is likely to fuel an "us/them" mentality, because in a fight situation we need an enemy to hate. Especially when we haven't fully examined the range of our own emotions, we are likely to identify an "enemy" prematurely and to categorize some people as the "enemy" so that we can have a target for our anger.

Although this response of anger, rage, and hatred is understandable, it is likely to cause all sorts of additional harm if left unchecked. Fortunately, human beings are not restricted to basic physiological reactions to threat. As mature individuals, and particularly as a community, we can work together to respond to our current situation constructively. A first step for many of us is to acknowledge the complexity and range of our emotional responses. 
It is also fortunate that humans, as social creatures, do have a constructive alternative to the flight-or-fight reaction to threat. This social reaction to threat has recently been termed "tend-and-befriend" (Taylor et al., 2000) Acts of caring and compassion and unity can help us. Psychologists studying tend-and-befriend responses have suggested that there is a physiological basis for this response as well. It is clearly better suited for many threat situations (Taylor et al., 2000). The current terrorist attack is a great example of where tend-and-befriend will likely help us, whereas flight-or-fight will likely lead us to further harm.

It is important for people's own well-being, as well as the safety of those around them, that they take care to avoid hiding behind anger. How to do this? Reflect, write, talk. Most people will have real and legitimate anger in response to the events on September 11, but in addition to the anger, other feelings are extremely important to acknowledge.

In this particular case there is a very specific way we can proceed constructively: In addition to offering help to victims of the September 11 tragedy, also acknowledge the risk that in our anger we may lash out at innocent targets, such as "all Arabs" or "all Muslims." Then reach out to an Arab or Muslim friend or acquaintance, express concern and willingness to help, and encourage him or her to talk about this tragedy; you'll probably find yourself listening to a somewhat different perspective from yours. Take the step now to offer comfort to innocent people who are most likely to be hurt as we go forward. Doing this will help you too-it's not just for your Arab or Muslim friend. It will help you understand your own feelings of anger, fear, and sadness. It will help you be part of a larger community. In turn, the community, the country, indeed the world, will benefit from your tending and befriending.

\section{References}

cnn.com (2001, September 17). Hate crime reports up in wake of terrorist attacks. CNN.com./U.S. Available: http://www.cnn.com/2001/US/09/16/gen.hate.crimes/

Maier, S. F., Watkins, L. R., \& Fleshner, M. (1994). Psychoneuroimmunology: The interface between behavior, brain, and immunity. American Psychologist, 49, 1004-1017.

Pennebaker, J. W. (1997). Writing about emotional experiences as a therapeutic process. Psychological Science, 8(3), 162-166.

Shay, J. (1994). Achilles in Vietnam: Combat trauma and the undoing of character. New York: Atheneum.

Taylor, S. E., Klein, L. C., Lewis, B. P., Gruenewald, T. L., Gurung, R. A. R., \& Updegraff, J. A. (2000). Biobehavioral responses to stress in females: Tend-and-befriend, not fight-or-flight. Psychological Review, 107, 411-429.

Thomson, D. (2001, September 14). Arab-Americans feel backlash. ABCNEWS.com. Available: http://abcnews.go.com/sections/us/DailyNews/wtc_backlash_010914.html

JENNIFER J. FREYD is Professor of Psychology at the University of Oregon. Freyd's book Betrayal Trauma: The Logic of Forgetting Childhood Abuse was published in 1996 by Harvard University. Freyd is the coeditor of a new book, 
Trauma \& Cognitive Science, published by Haworth Press in 2001. Readers are invited to visit Freyd's web site at http://dynamic.uoregon.edu/ 